\title{
Supporting Components of Behavior Science Literacy for Elementary Students in Adiwiyata's School
}

\author{
Safrizal ${ }^{1 *}$, Resti Yulia ${ }^{2}$ \\ \{safrizal@iainbatusangkar.ac.id ${ }^{1 *}$, restiyulia911@gmail.com ${ }^{2}$ \} \\ ${ }^{1}$ Primary Education, Faculty Tarbiyah and Teacher Training, Institut Agama Islam Negeri Batusangkar, \\ Jl. Jend. Sudirman No. 137 Kuburajo Lima Kaum, Tanah Datar Indonesia \\ ${ }^{2}$ Childhood Education, Faculty of Education, Universitas Negeri Padang, Jln. Prof. Dr. Hamka, Air \\ Tawar, Padang, Sumatra Barat, Indonesia
}

\begin{abstract}
Scientific literacy is seen as one of the 21st century skills that must be developed in students. The importance of developing scientific literacy behavior among students is expected to be a solution in increasing understanding in applying scientific concepts to solving problems of everyday life. Currently Adiwiyata school is one that accommodates the formation of scientific literacy behavior. The purpose of this study was to describe the supporting components in shaping scientific literacy behavior in elementary school students at Adiwiyata School. This research uses descriptive qualitative type with the researcher as the key instrument. Research data collection was carried out in three steps, in-depth interviews, participant-based observation, and documentation of activities. To ensure the accuracy of the data, researchers analyzed using the Miles and Huberman model, while ensuring the validity of the data triangulation was one of the techniques used. The results showed that there were two supporting components in shaping the science literacy behavior of elementary school students in Adiwiyata schools, namely the human and non-human components. These two components are key in shaping students' scientific literacy behavior at Adiwiyata school.
\end{abstract}

Keywords: Science Literacy, Adiwiyata's School, Supporting Component Science Literacy.

\section{Introduction}

Scientific literacy or better known as scientific literacy is one of the 21 st century skills that the current generation must have [1], [2], [4], [5]. The strong reason for the importance of scientific literacy as one of the skills of the 21 st century is due to changes in world order which not only require a generation that is rich in theory but a generation that has the skills to apply scientific skills to serve as problem solving or problem solving in everyday life [6]-[9]. In a simple concept, scientific literacy essentially refers to the basic knowledge that students need to understand science, so that students can use this information to make decisions about personal, civil, and economic matters [10], [11]. Several definitions related to scientific literacy are explained by several scientists, namely scientific literacy is seen as the capacity to use scientific knowledge to identify various questions and problems to the ability to analyze and draw conclusions based on the concepts of knowledge that have been obtained [12]-[14]. In other words, scientific literacy refers to an understanding of skills in processing scientific knowledge based on cognitive abilities to be used and applied as a problem solving tool in everyday life. 
The importance of developing scientific literacy in elementary school students is a strategy to maintain growth spikes and prepare a demographic bonus in terms of increasing application capabilities, as well as determining the human development index in Indonesia [4], [5], [14]. That way, it is clear that scientific literacy is seen as one of the abilities that must be built in the education system, especially at the primary school level. The importance of developing scientific literacy is also based on several problems related to students' scientific literacy skills in the world arena which continues to decline. Dilangsir from the Program for International Student Assessment (PISA) in 2015 - Now scientific literacy skills are still below the world average [15]-[17]. This indicates that the quality of learning and education in our country still requires maximum effort and superior programs to solve this problem. Problems related to low scientific literacy skills were answered by the presence of the Adiwiyata program launched by the government with the main objective of creating students with an environmental culture [4], [14], [18]. This effort was launched with the aim of providing understanding and inculcating attitudes and behaviors on how to empower nature in such a way that it can provide opportunities for each student to create a sustainable living environment. Thus, Adiwiyata is a strong reason for the government's move to form a generation that is information literate and has the initiative to make the environment a basis for sustainable living.

In several studies, Adiwiyata School has specific specifications in carrying out its objectives as a school with environmental care standards. The results of preliminary observations indicate some of the advantages of Adiwiyata school, including the shady school environment that allows it to provide comfort for students in carrying out learning. Besides that, cleanliness is also a highlighted part of Adiwiyata school, so it is very familiar to see students throwing garbage in its place. These initial findings are reinforced by several research results that Adiwiyata schools with environmental care programs prioritize cleanliness and school beauty as support and comfort for children in learning. Therefore, this specification attracts the attention of researchers to carry out research in Adiwiyata schools, especially in the formation of scientific literacy behavior. Thus, it is clear that the purpose of this study is to describe the supporting components in shaping the scientific literacy behavior of elementary school students in Adiwiyata schools.

\section{Method}

The research method used descriptive qualitative. This type of research was selected based on the problem criteria that will be presented in the form of a description of words or findings in the field based on written information and oral information from people who are research subjects [19]. The informants of this study were selected using a snowball sampling technique consisting of the headmaster, teachers, education personnel, students, and the canteen keeper and school cleaners. The data collection process in this study was carried out in the form of indepth interviews, participant observation, and documentation study related to the problems and research findings. To support accurate data collection, researchers are used as a key instrument. Data analysis was carried out by referring to the Miles and Huberman model which consists of data reduction, data display and conclusion drawing. In order for the research results to be accurate and valid, the researcher uses triangulation techniques and extends the research time by increasing the persistence of the research findings that have been collected. 


\section{Results and Discussion}

The supporting components for the formation of scientific literacy behavior found in SD Adiwiyata X Padang City are special findings in this research study. Findings related to the supporting components in shaping students' scientific literacy behavior are summarized in the results of interviews, observations, and documentation of activities. So that the researchers specifically summarize it into two categories, namely the human component and the non-human component.

\subsection{The Human Component for Behavior Science Literacy in Adiwiyata's School}

The human component is a supporting instrument based on individuals or people around the school who play a role in shaping students' scientific literacy behavior. This finding is based on the results of interviews conducted by a number of informants and the results of observations while at school. Several findings related to the human component in shaping scientific literacy behavior, such as interviews conducted by curriculum representatives and teachers in schools, explained that the formation of scientific literacy behavior was supported by teachers as facilitators in providing guidance during the learning process.

"The process of inculcating scientific literacy behavior is usually carried out by teachers during the learning process, for example by inviting children to practice making traditional medicines from various medicinal plants in the school environment as first aid."

The above statement, also mentioned by a number of students at the school, that they justify if the teacher always invites them to solve problems related to science in the learning process through teacher guidance.

"Usually the teacher always guides us to solve problems related to science through the introduction of plants that can be used as traditional medicine, we have also used this medicinal plant to treat a friend who had a nosebleed."

In addition to teachers, students who are fostered as little doctors also help teachers become peer tutors in practicing some scientific processes that can be done by solving them based on scientific literacy. Such as decomposers, making medicinal plants into traditional medicines, as well as reprimanding students who litter, and being a monitoring team for students who use water excessively. Specifically, it is depicted in the following diagram.

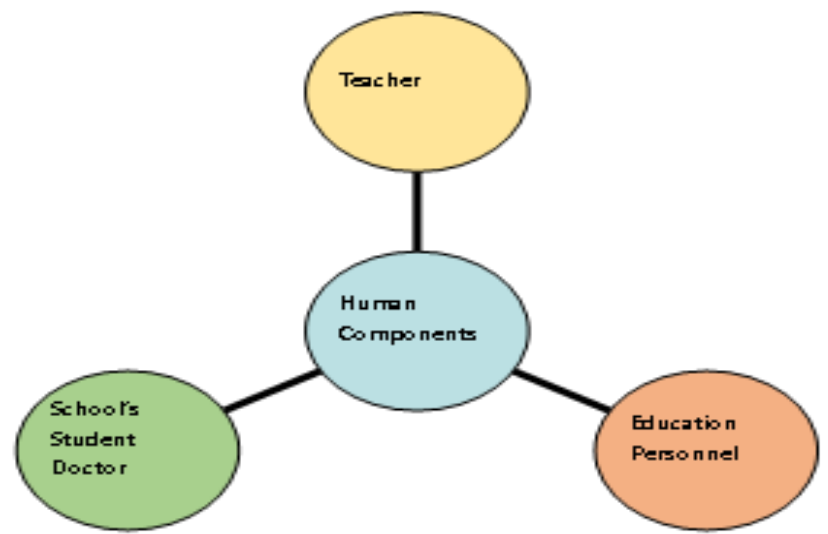

Fig. 1. Human's Component for Behavior Science Literacy in Adiwiyata’s School 
Teacher. Data related to the role of the teacher as a supporting component in shaping students' scientific literacy behavior in Adiwiyata Elementary School can be seen from its function which is more focused on its role as a facilitator with guidance, direction, and giving examples carried out by students as the data obtained shows that the formation of scientific literacy carried out by The teacher is more directing to the learning process and directing the habituation of environmental care behavior by applying the functions and uses of various learning components obtained from the school environment, so that this is an example for students in applying and applying science principles in solving everyday problems.

School's Student Doctor. This component is used as a reference by peers in assisting the teacher to re-explain the information and knowledge obtained. So that the little doctor is used as a substitute for the teacher in introducing the various properties of various plants in schools as an alternative to first aid medicine and has the function of supervising and imposing sanctions for friends who throw garbage inappropriately. So that the presence of a little doctor becomes an instrument to provide education related to the introduction of plants and their functions to peers. In addition, the little doctor also provides education related to the practice of making decomposers which will be socialized to friends at school.

Education Personnel. All individuals who enter the school area at SD Adiwiyata are a supporting component for the formation of scientific literacy behavior. School employees are interpreted as individuals who work in the school area other than teachers and school principals, in this case the cleaners, canteen keepers, and school guards. Their involvement in shaping scientific literacy lies in serving healthy food and in an orderly way to the cleanliness of the school environment. The contribution generated from this component lies in the explanation related to healthy and suitable food for consumption, so that students are trained and accustomed to choosing snacks that have health standards for consumption by the body.

\subsection{The Non-human Component for Behavior Science Literacy in Adiwiyata's School}

The non-human component becomes the second subject in shaping scientific literacy behavior. This component is defined as objects in the vicinity of the school that provide an effect on the formation of scientific literacy behavior. It is simply seen in the following picture.

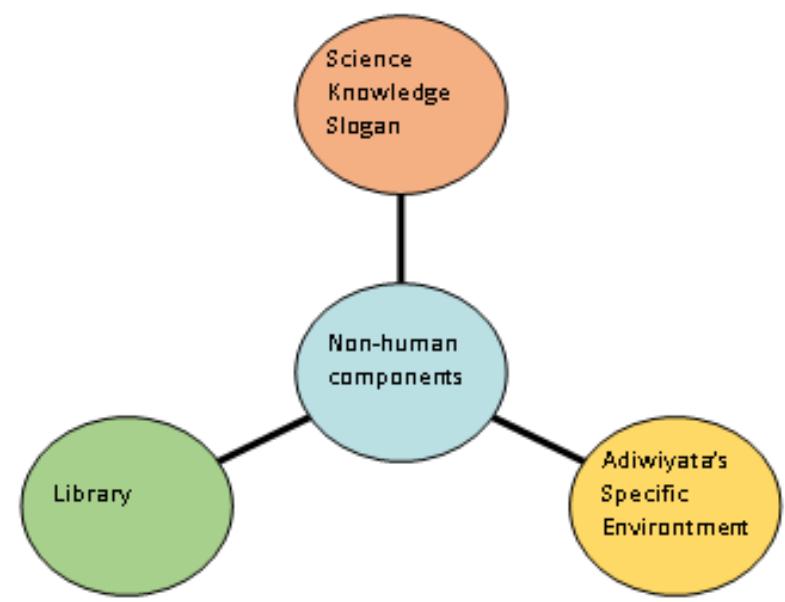

Fig. 3. Non-human Component for Supporting Behavior Science Literacy in Adiwiyata's School. 
Science Knowledge Slogan. The findings of this component are in the form of slogans linked to various scientific knowledge that are stuck on the walls of every corner of the school. The slogan which contains knowledge is held not only as part of adiwiyata, but rather leads to the inculcation of attitudes and providing information and additional insights in the scientific field which are sometimes missed by the teacher's explanation, thus the slogan of science knowledge is often used by children and teachers as a learning medium. in developing knowledge and shaping student attitudes.

Library. The library is one of the places for students to find various information from available source books. Apart from being a place to read, the library is also a means for students to solve problems given by the teacher. This means that the existence of a library has a positive impact on children's knowledge of information. So that this will add to their insight in applying one discipline to solve everyday problems.

Adiwiyata Specific Environment. Adiwiyata is a title for schools that have environmental care programs. The specific environment owned by Adiwiyata school is a garden and various plant specifications that have scientific names and explanations for their functions, family medicinal plants (TOGA), greenhouses, and decomposters. This specific environmental component provides students with understanding and knowledge so that they can apply the knowledge they acquire in everyday life. This can be seen in the research data that the Adiwiyata specific environment provides learning experiences for students on how to care for plants, utilizing plants as medicine and first aid for accidents, and utilizing waste as compost so that it will add insight to students regarding their knowledge of the world of science and its functions.

The findings of the components supporting the formation of students' scientific literacy behavior at the Adiwiyata Mandiri school, one of which was the finding of many slogans related to various scientific knowledge that were plastered on the walls in every corner of the class. Procurement of slogans scattered in every corner of the classroom walls of course has a specific purpose. This means that the slogan is not only part of Adiwiyata but rather to inculcate attitudes and provide information through slogans as a daily learning medium that is seen by students, so that this will add understanding to students' knowledge and learning experiences. In particular, the purpose of procuring slogans and images related to the appeal as described above, was taken based on some data from interviews and field findings summarized in field notes. This is, as the data from interviews with informants.

"Non-human components, which consist of libraries, slogans, and adiwiyata specific environment, are generally used as tools for the learning process. So that the message of scientific literacy and the importance of having scientific literacy behavior is formed. In addition, this specific presentation helps to make it easier to instill and shape students' scientific literacy behavior." 
Figure on slogan and written messages from the slogans include scientific knowledge, appeals to save electricity and water, LIBAS (Waste-Free Environment), P3 (Dyes, Preservatives, and Sweeteners), as well as being smart consumers, appeals to wash hands before eating, as well as various images other knowledge. The pictures of scientific knowledge slogans displayed along the walls of the classroom tell about the metamorphosis of a butterfly as it is contained in the content of science learning in grade IV. The pictures of other scientific knowledge slogans that can be seen in schools are pictures of the occurrence of the rain cycle. This picture tells about the flow or cycle of rain. This material will also be found in the content of science subjects in grades IV and V. Several other slogans such as knowledge about P3 (Preservatives, Sweeteners, Dyes) are also visible on the walls of the school.

Procurement Slogans scattered in every corner of the classroom walls have a specific purpose. This means that the slogan is not only part of Adiwiyata but rather to inculcate attitudes and provide information through slogans as a daily learning medium that is seen by students, so that this will add understanding to students' knowledge and learning experiences. In particular, the purpose of procuring slogans and images related to the appeal as described above, was taken based on some data from interviews and field findings summarized in field notes.

Based on several findings that have been described related to the supporting components of scientific literacy, essentially directs to one main focus, namely the conveying media. In the concept of social learning theory proposed by Bandura, it is stated that behavior formation is an association of behavior, environment, and person. This understanding can be explained that the supporting component in the formation of behavior is an environment that will have an impact on the birth of behavior, while behavior is the resultant or the result of the accumulation of roles between the surrounding people and their environment [13], [20], [21]. This is in line with the results of the study that the human and non-human components have a big share in the process of shaping scientific literacy behavior. The human component which refers to individuals who enter the realm of school organizations becomes a model as well as a facilitator in displaying and exemplifying good things to students in cultivating scientific literacy behavior. The example provided by the human component shows the association of observational learning theory which believes that people can learn by observing other people and by doing things that are learned.

The description above gives the meaning of the human component which includes teachers, little doctors, and school employees who are companions, coaches, and facilitators of students in helping to understand science literacy behavior. The presence of the human component provides its own andl as a model to be emulated by students in schools [22]-[24]. The reflection of scientific literacy behavior displayed by this supporting component is an example in providing knowledge, helping friends who are sick, and maintaining cleanliness as part of environmental care. So if you think of a little doctor plane as a flight attendant / a who will help facilitate the understanding of his colleagues, school employees are delivering healthy food, while the teacher is a pilot who will steer the direction of the plane according to the coordinates of the direction taken. 
The second component as a support in shaping scientific literacy behavior is non-human which includes the slogan of scientific knowledge, libraries, and the specific Adiwiyata environment. This component focuses on the learning messages contained in each of its functions. In the cone of learning that was initiated by Dale, he argued that $50 \%$ of students' experiences were derived from what they saw and heard [13], [25]. This description makes it clear that the maximum use and utilization of slogans with teacher guidance can increase $50 \%$ of the student learning experience. In a psychological review, the slogan of scientific knowledge becomes one of the media that causes changes in learning behavior because of the learning experiences obtained based on the results of their vision. Dahar also expressed the same opinion that the information obtained as a way to solve problems is closely related to conturctivism theory that the construction of personal knowledge through individual interaction with the environment is important as an effort to internalize difficult understandings, problems, and processes [13], [20], [26]. This opinion is a strong reason that the information that students get through the slogan of science knowledge, libraries and the specific Adiwiyata environment provides additional experience and knowledge in solving everyday problems.

Environmental education which is attached to the main objective of the Adiwiyata program in schools is not only in the form of theory, but rather as a cultural practice. To accommodate this goal, Adiwiyata specific environment exists as a means of supporting the formation of an environmentally friendly culture. Some opinions suggest that a school environment that looks more natural leads to a lot of knowledge that students carry, great experiences, and a deeper aesthetic sense [13], [26]-[28]. In addition, the Adiwiyata specific environment can be used as a learning laboratory for students as a component in shaping scientific literacy behavior.

\section{Conclusion}

The conclusion of the research is the components that form scientific literacy in Adiwiyata schools basically include two things, namely the human and non-human components. The human component is an individual who is in the scope of the school who participates in upholding school principles and rules, including teachers, little doctors, and school employees. Meanwhile, non-human components are instruments, tools, or objects that have a role in the process of adding students' insights and understanding related to scientific literacy, which includes the slogan of scientific knowledge, libraries, and the specific adiwiyata environment. these two components are key findings that can help develop students' scientific literacy behavior in schools. In addition, students' understanding in solving problems related to science is also obtained through these two components.

\section{References}

[1] J. L. Docktor, N. E. Strand, J. P. Mestre, and B. H. Ross, "Conceptual problem solving in high school physics,” Phys. Rev. Spec. Top. - Phys. Educ. Res., vol. 11, no. 2, pp. 1-13, 2015, doi: 10.1103/PhysRevSTPER.11.020106.

[2] B. Hegde and B. N. Meera, "How do they solve it? An insight into the learner's approach to the mechanism of physics problem solving," Phys. Rev. Spec. Top. - Phys. Educ. Res., vol. 8, no. 1, pp. 1-9, 2012, doi: 10.1103/PhysRevSTPER.8.010109.

[3] J. L. Docktor and J. P. Mestre, "Synthesis of discipline-based education research in physics," Phys. Rev. Spec. Top. - Phys. Educ. Res., vol. 10, no. 2, pp. 1-58, 2014, doi: 10.1103/PhysRevSTPER.10.020119.

[4] M. De Cock, "Representation use and strategy choice in physics problem solving," Phys. Rev. Spec. Top. - Phys. Educ. Res., vol. 8, no. 2, pp. 1-15, 2012, doi: 10.1103/PhysRevSTPER.8.020117. 
[5] D. E. Meltzer, "Relation between students' problem-solving performance and representational format," Am. J. Phys., vol. 73, no. 5, pp. 463-478, 2005, doi: 10.1119/1.1862636.

[6] A. Lichtenberger, C. Wagner, S. I. Hofer, E. Stern, and A. Vaterlaus, "Validation and structural analysis of the kinematics concept test,” Phys. Rev. Phys. Educ. Res., vol. 13, no. 1, pp. 1-13, 2017, doi: 10.1103/PhysRevPhysEducRes.13.010115.

[7] M. Planinic, L. Ivanjek, A. Susac, and Z. Milin-Sipus, "Comparison of university students' understanding of graphs in different contexts,” Phys. Rev. Spec. Top. - Phys. Educ. Res., vol. 9, no. 2, pp. 1-9, 2013, doi: 10.1103/PhysRevSTPER.9.020103.

[8] D. Sarkity and P. D. Sundari, "Pemahaman Konsep Fisika Calon Guru Biologi Pada Topik Kinematika," Pdagog. Hayati J. Ilm. Pendidik. Biol., vol. 4, no. 2, pp. 106-116, 2020.

[9] M. R. A. Taqwa, A. Hidayat, and S. Sutopo, "Konsistensi Pemahaman Konsep Kecepatan dalam Berbagai Representasi," J. Ris. dan Kaji. Pendidik. Fis., vol. 4, no. 1, p. 31, 2017, doi: 10.12928/jrkpf.v4i1.6469.

[10] D. E. Trowbridge and L. C. McDermott, "Investigation of student understanding of the concept of velocity in one dimension," Am. J. Phys., vol. 48, no. 12, pp. 1020-1028, 1980, doi: 10.1119/1.12298.

[11] S. Sutopo, P. Parno, and S. L. Angin, "Pemahaman Mahasiswa Tentang Multi Representasi Konsep Percepatan,” J. Ris. dan Kaji. Pendidik. Fis., vol. 4, no. 2, p. 48, 2017, doi: 10.12928/jrkpf.v4i2.6551.

[12] M. I. Shodiqin and M. R. A. Taqwa, "Identification of student difficulties in understanding kinematics : focus of study on the topic of acceleration Identification of student difficulties in understanding kinematics: focus of study on the topic of acceleration," pp. 0-5, 2021, doi: 10.1088/1742-6596/1918/2/022016.

[13] A. Jufriadi, S. Kusairi, and S. Sutopo, "Exploration of student's understanding of distance and displacement concept," J. Phys. Conf. Ser., vol. 1869, no. 1, pp. 0-6, 2021, doi: 10.1088/17426596/1869/1/012195.

[14] A. Zainuddin, S. Kusairi, and S. Zulaikah, "Kesulitan Mahasiswa Dalam Memahami Konsep Kinematika Gerak 1 Dimensi,” J. Pendidik. Teor. Penelitian, dan Pengemb., vol. 4, no. 1, pp. 56-60, 2019.

[15] J. Bowden et al., "Displacement, velocity, and frames of reference: Phenomenographic studies of students' understanding and some implications for teaching and assessment," Am. J. Phys., vol. 60, no. 3, pp. 262-269, 1992, doi: 10.1119/1.16907.

[16] S. Syuhendri, "Effect of conceptual change texts on physics education students' conceptual understanding in kinematics," J. Phys. Conf. Ser., vol. 1876, no. 1, pp. 0-8, 2021, doi: 10.1088/17426596/1876/1/012090.

[17] G. Zavala, S. Tejeda, P. Barniol, and R. J. Beichner, "Modifying the test of understanding graphs in kinematics," Phys. Rev. Phys. Educ. Res., vol. 13, no. 2, pp. 1-16, 2017, doi: 10.1103/PhysRevPhysEducRes.13.020111.

[18] V. Antwi, E. Savelsbergh, and H. Eijkelhof, "Understanding kinematics graphs using MBL tools, simulations and graph samples in an interactive engagement context in a Ghanaian university," J. Phys. Conf. Ser., vol. 1076, no. 1, pp. 0-9, 2018, doi: 10.1088/1742-6596/1076/1/012002.

[19] V. R. Riani, L. H. Sa'Diyah, M. G. Purwanto, T. R. Ramalis, and A. Samsudin, “Assessing graph interpretation of high school students: An examination by students' gender," J. Phys. Conf. Ser., vol. 1806, no. 1, pp. 0-7, 2021, doi: 10.1088/1742-6596/1806/1/012011.

[20] S. Ceuppens, L. Bollen, J. Deprez, W. Dehaene, and M. De Cock, "9th grade students' understanding and strategies when solving $\mathrm{x}(\mathrm{t})$ problems in 1D kinematics and $\mathrm{y}(\mathrm{x})$ problems in mathematics," Phys. Rev. Phys. Educ. Res., vol. 15, no. 1, p. 10101, 2019, doi: 10.1103/PhysRevPhysEducRes.15.010101.

[21] A. Maries and C. Singh, "Exploring one aspect of pedagogical content knowledge of teaching assistants using the test of understanding graphs in kinematics," Phys. Rev. Spec. Top. - Phys. Educ. Res., vol. 9, no. 2, pp. 1-14, 2013, doi: 10.1103/PhysRevSTPER.9.020120.

[22] W. M. Christensen and J. R. Thompson, "Investigating graphical representations of slope and derivative without a physics context,” Phys. Rev. Spec. Top. - Phys. Educ. Res., vol. 8, no. 2, pp. 15, 2012, doi: 10.1103/PhysRevSTPER.8.023101. 
[23] L. Bollen, M. De Cock, K. Zuza, J. Guisasola, and P. Van Kampen, "Generalizing a categorization of students' interpretations of linear kinematics graphs,” Phys. Rev. Phys. Educ. Res., vol. 12, no. 1, pp. 1-10, 2016, doi: 10.1103/PhysRevPhysEducRes.12.010108. 